\title{
10
}

\section{Life Design for an Inclusive and Sustainable Future}

\author{
Ilaria Di Maggio, Maria Cristina Ginevra, Sara Santilli, \\ Laura Nota, and Salvatore Soresi
}

We live in a world characterized by uncertainty, complexity, rapid change, globalization, and inequality, all of which has significant impact on the wellbeing of people, groups, and communities. Further, it seems clear that the world is in the midst of significant ideological, social, and environmental changes (Hooley, Sultana, \& Thomsen, 2018). These changes make it more difficult not only for a great part of the population to live in the present, but also for succeeding generations to aspire to and imagine a possible future (Guichard, 2018; Hooley et al., 2018; Santilli, Di Maggio, Ginevra, Nota, \& Soresi, 2020).

From the 1970s to the present, a neoliberal vision of markets and the economy permeated, little by little, cultures, education, and the role of citizenship, infusing the idea that the wellbeing of the person is related to consumption and the ownership of objects and items (Guichard, 2018; Santilli et al., 2020). As a result, there is a saturation of market-related models in many different areas of human, social, and political life. Too often, in this context, people look for happiness and wellbeing in new products, new markets, and new ideas, and competition is considered a source of social progress (Dardot \& Laval, 2013).

Moreover, processes such as globalization, understood mainly in terms of the free movement of capital, brought a shift of production systems in developing countries. These forces brought higher availability of low-cost "global

I. Di Maggio · M. C. Ginevra · S. Santilli · L. Nota $(\bowtie) \cdot S$. Soresi University of Padova, Padua, Italy

e-mail: laura.nota@unipd.it 
manpower,' while also bringing the loss, in Western countries, of a considerable number of workplaces and positions (Chomsky \& Polychroniou, 2018). All of this has been exacerbated and augmented by rapid automation that has fostered the substitution of routine jobs with technology, reducing further the possibilities for work for a wider swath of the population (Milanovic, 2017).

These realities dominate the contexts in most countries, resulting too often in inequalities and the exclusion of a significant number of people (from the most vulnerable to middle-class people) who, previously, were protected (Alvaredo, Chancel, Piketty, Saez, \& Zucman, 2018; Milanovic, 2017). Moreover, there is a contrast between Western countries and developing countries: in the former, there is the centralization of capital, techniques, and comforts, while in the latter there is, too often, despair and desolation. Consequently, it is reasonable to hypothesize that emigration could exponentially increase over the next decade, exacerbating problems such as poverty, consistent levels of social heterogeneity, high competitiveness, precariousness, and excessive exploitation of natural resources (Nota, Soresi, Di Maggio, Santilli, \& Ginevra, 2020).

One implication of this somewhat gloomy forecast is the need to revise multiple assumptions of and processes pertaining to career guidance and the changing shape of careers and the world of work. Being alert to issues of inclusion and sustainability will be even more important in the future, and professionals in career and vocational guidance will need to be trained to recognize discrimination, address inequalities, remove barriers, and minimize exploitation; to focus on the overall wellbeing of humanity and of the world we live in, particularly where people from younger generations will live (Hooley et al., 2018; Nota et al., 2020).

In this chapter, following a brief historical excursion through the social role that career guidance has had through the years, we outline possible actions that career guidance professionals could perform so as to embrace, sustain, and foster the creation of a better future for everyone and to contribute to the creation of inclusive and sustainable societies.

\section{Career Guidance, Career Design, and Career Counselling: Past, Present, and Future}

For much of recent history, a number of presumptions about careers and work prevailed and shaped career guidance: work and workplaces were reliably stable; there were enough jobs available that workers could choose what they 
wanted, particularly in the wealthiest countries; and getting adequate education and training would almost guarantee employment in a timely manner. The role of career guidance and counsellors in such a context was to assist young people to choose among different career options based upon factors related to ability and interest. As such, the field of career guidance has studied and applied criteria and tools to analyse the relationships between supply and demand so as to predict job availability.

Parsons (1909) is credited with establishing these "matching" practices in career guidance, proposing that guidance counsellors identify aptitudes and match them to work contexts and demands. Within this model, the counsellor expends time and effort to identify a person's aptitudes, including sensory and physical skills, cognitive and emotional capacities, and the person's interests when providing career guidance (Nota \& Rossier, 2015; Savickas, 2011; Savickas et al., 2009).

This course of action in the field of career guidance brought about tremendous social change, since before that time people were "trapped" in their social class: there were no jobs to choose or to be prepared for if a person was not in a certain social stratum. School success (and thus school opportunity), during this time, was characterized as confirming one's social status. Career guidance provided opportunities to individuals who, previously, had no such chances and emphasized their rights to choose employment and a career by, in essence, serving as a mediator "between" the career environment and the person.

The social context that inspired Parsons and his followers began to change after the end of the Second World War, once again bringing about radical social changes. During these years, there was a higher demand for skilled labour, both in technical and clerical fields. Education finally became an investment for the economic growth of countries. Employment opportunities, higher educational attainment levels, the widening of rights and civic protections for marginalized people, and increased attention to the population's wellbeing: all these factors contributed to focus attention on career choices and themes such as career fulfilment. The idea of "career" started to take hold in career guidance activities.

Accordingly — and paralleling the development of psychological, educational, and social science studies pertaining to career and work-career guidance processes began to take into account greater complexity. Rather than focusing only on what Parsons referred to as "interests," career and vocational guidance counsellors and theorists incorporated knowledge about personality and motivation, with the idea that if such traits are nurtured in specific career environments, it could foster both career fulfilment and enhanced career performance (Holland, 1959). 
Thus, variables such as motivation, knowledge, skills, career values, and personal characteristics required more attention from guidance counsellors. These variables eventually began to be seen as interconnected with contextual factors, such as emphasized in Social-Cognitive Career Theory by Lent, Brown, and Hackett (1994). Career decision-making models were formulated to assist people in making career choices (e.g., Gati, Garty, \& Fassa, 1996). The idea of career development took on a major role in theory and practice with the recognition that, like other areas of human development, career interests, preferences, and knowledge developed over time. Donald Super (1980), for example, introduced an early theory of career development, the Life Career Rainbow, which described career development in terms of life stages and life roles, providing fruitful ideas and information for both practitioners and researchers.

Super's theoretical framework was extended, expanded, and renewed by Savickas, who, during the 1990s, proposed Career Construction Theory (Savickas, 2005), which lies at the heart of the Life Design paradigm (Savickas et al., 2009), as described below.

\section{The Life Design Approach}

The Life Design International Research Group emerged in the period when the world was facing the economic crisis of the 2008 Great Recession. The causes of the crisis were complex and not clear to many people who, too often, experienced job losses, increased unemployment, and increased job insecurity levels (Nota, Soresi, Ferrari, \& Ginevra, 2014; O’Reilly, Lain, Sheehan, Smale, \& Stuart, 2011). There arose a need to begin to provide solutions to problems and discomforts that were becoming more and more consistent, by looking for new ways to deal with a reality that was still not so understandable.

The Life Design paradigm, based on the epistemology of social constructivism (Young \& Collin, 2004), recognized that professional development is highly contextualized and individualized. It claims that career development cannot only focus on career decisions regarding finding a suitable job according to personal competences, values, and interests. Rather, it conceptualizes career development as a dynamic interaction between personal characteristics and contextual factors. Specifically, according to this paradigm, the individual is an active agent and actor of their own personal and career development, of their present and future, by designing their life stories or narratives and formulating coherent life aims and plans (Pouyaud, 2015; 
Wehmeyer et al., 2019). They are not shaped by the context, but is in interdependence with it. This means that the individual develops in a specific social and cultural context, which involves multiple systems (e.g., organizations, societal policies, and practices), which can affect human functioning (Nota \& Rossier, 2015). As a result, focusing exclusively on environmental conditions or individual attitudes, interests, and abilities as a basis for successful career development is not enough; instead career counselling should focus on how these multiple nonlinear interactions can have a positive impact on career and life outcomes (Hirschi \& Dauwalder, 2015).

The Life Design paradigm underlines the need for supporting individuals in co-constructing and planning personal and professional pathways. Career designing should be the result of a continuous construction and reconstruction of life themes that include past memories, present experiences, and future aspirations (Pouyaud, 2015). The personal meaning of these themes allows individuals to adapt to social changes that are crucial in their working lives (Savickas et al., 2009). Therefore, life designing is a dynamic, recursive, and strategic process that should not be detached from self-reflection, taking into account the numerous experiences and time of life (past, present, and future) together with the diverse contexts and roles everyone can play during their existence.

The Life Design paradigm, as described by its founding group in the 2009 article (Savickas et al., 2009), was built on five premises:

(1) From Traits and States to Context. The suggestion was to move beyond objective measurements and regulatory profiles, which turned out to be inadequate in describing people as living beings that interact and adjust to multiple contexts. Professional identities should be considered as variable patterns influenced by stories and not representable by static, conceptual, and simplified profiles, built with scores obtained through tests.

(2) From Prescription to Process. The idea was to move from traditional processes involving giving direction and advice about a career to follow to focusing on promoting coping strategies to enable clients to manage and deal with the complexity of a labour market characterized by frequent job changes and multiple choices and decisions throughout one's professional life.

(3) From Linear Causality to Non-linear Dynamics. People's professional lives are a complex phenomenon that cannot be dealt with using linear prediction modalities. Working activities will evolve, will be more 
complex and, there will be the need for analytic skills that enable one to focus on more holistic life projects.

(4) From Scientific Facts to Narrative Realities. There was particular attention to the necessity to take into consideration the constant construction and reconstruction of people's multiple, subjective realities. Rather than referring to group rules and conceptual terms, clients should be involved in activities that help them give meaning to their situation and, as a consequence, to look for new ways to see themselves.

(5) From Describing to Modelling. Clients' professional plans are, by definition, personal, therefore unique. As a consequence, efficient career counselling has to be adjusted in every single case. Every standardized activity reduces the value of such counselling.

The studies that took inspiration from the Life Design approach allowed the field to underline the need to proceed with customized, personalized actions. Moreover, it allowed the field to take into consideration people's right to receive specific attention, avoiding more standardized career guidance activities, which may be damaging because they do not account for the uniqueness of every person (Savickas et al., 2009). In the Life Design approach, more value was given to unique possibilities, opportunities, and, even, to unexpected outcomes. The authors of the stories used in such counselling have been encouraged and motivated to build, or instead to co-build, unique conclusions, new projects, and new stories for clients (Nota \& Rossier, 2015). Rather than considering, measuring, and evaluating those aspects that in the past were considered the most important predictors of academic and career success (such as interests, aptitudes, skills, leadership, motivation, etc.), career practitioners should focus on other factors. More specifically, they should support clients to consider issues regarding career adaptability, the potential benefits of investment in education, resilience, hope, optimism, and taking events in perspective (Nota \& Rossier, 2015). Under prior socioeconomic contexts, career guidance aimed to promote skills useful for career choice processes, focusing on enabling clients so that their working life could become a source of wellness. In this way, it was faithful to the mission of discipline with regard to social relevance (Soresi \& Nota, 2020).

Nowadays, however, the living conditions of people have changed considerably when compared to the past. Wellbeing seems to be a condition achieved by fewer people. Traditional processes used to support career choice and inclusion are no longer sufficient. Today, career practitioners have to consider that supporting clients to deal with the future means reflecting on how to face alarming risks. Some of these risks are, for example, increasing 
inequality, the concentration of prosperity and of work opportunities within an increasingly narrow band of people, the increasing movement of peoples across borders, the depletion of natural resources, the impact of technology on working environments and on quality of life, and job conditions that are at the same time more insecure and less decent. Another risk is the paradoxical request addressed to people to become, despite everything mentioned, more competitive and more resilient: people have to be "constantly" ready and good enough to deal with unpredictable opportunities. People are also expected to become self-entrepreneurs, even without the actual amount of money that is required to start such a career (Hooley et al., 2018; Nota et al., 2020).

Having considered all these factors, it is hard to escape the fact that career guidance needs a change of pace that, according to us, can only be associated with investments in inclusion and sustainability.

\section{Starting from Inclusion and Sustainability}

At the root of neoliberal economic ideas and policies that have characterized the last three decades, there is the individual. Too little attention has been given to social, societal, and social justice issues. But the global issues discussed previously are pushing the consideration of new strategies, embracing solidarity, mutual aid, a sense of societal responsibility, empathy towards the others, and, overall, inclusion and sustainability within and beyond national borders. These strategies can be used for economic growth and development (Hooley et al., 2018). Before describing the role of career guidance in the construction of inclusive and sustainable contexts, it is appropriate to define these two terms.

Inclusion. The term inclusion refers to contexts in which all people fully and actively participate in all aspects of society and in which they are able to obtain a satisfying quality of life (Di Maggio \& Shogren, 2017). When the term inclusion is used, the emphasis is not on what might make the person "different," whether referring to one's racial/ethnic, linguistic, disability, or socioeconomic status when compared with any other group, but instead, emphasis is placed on the interaction between what makes each person unique and how that contributes to improved social, civil, and career participation (Owens, 2015; Shogren, Wehmeyer, Schalock, \& Thompson, 2016).

Inclusion implies that all people and all institutions are "active" in seeking to guarantee the full participation of every person in social and civil life 
(Asante, 2002). In other words, promoting inclusion requires an emphasis on the contexts in which all people live, learn, work, and play (e.g., organizations, systems, and societal policies and practices), as these contexts play a critical role in promoting individuals' functioning and quality of life and the co-construction of their strengths and weaknesses (Asante, 2002; Shogren et al., 2016).

Sustainability. The United Nations adopted sustainable development as a guiding principle for economic, environmental, and social development. This principle aspires to meet "the needs of the present" without compromising the ability of future generations to meet their own needs and fosters an "equitable sharing of the environmental costs and benefits of economic development between and within countries" (World Commission on Environment and Development [WCED], 1987).

According to the Brundtland Report (WCED, 1987), sustainability involves the protection of the environment and natural resources. It also emphasizes social and economic welfare to present and subsequent generations. Sustainable development is also understood as socially just and ethically acceptable. Sustainability has thus been recognized as an essential normative principle for the society in establishing long-term ethical relationships between present and future generations (Hansmann, Miegb, \& Frischknecht, 2012). It is an integrative construct, which incorporates environmental, social, and economic factors as three fundamental dimensions. These three dimensions are pillars of sustainability: responsible development requires attention to the natural, human, and economic capital or, informally, the planet, the people, and the profits (Purvis, Mao, \& Robinson, 2019).

The above-mentioned is aligned with the 2030 Agenda for Sustainable Development and its 17 Sustainable Development Goals. This was adopted on 25 September 2015 at a special United Nations summit. The Agenda is a commitment to guarantee sustained and inclusive economic growth, social inclusion, and environmental protection; promoting peaceful, just, and inclusive societies through a new global partnership. As it pertains to this chapter, Goal 4 and Goal 8 are particularly relevant. Goal 4 emphasizes ensuring inclusive and equitable quality education and promoting lifelong learning opportunities for all individuals, especially for women, girls, and marginalized people in vulnerable environments. Goal 8 aims to promote inclusive and sustainable economic growth; full and productive employment, particularly for young people; and reduce informal employment and the gender pay gap while promoting safe and secure working environments so as to create decent work environments for every person. 
Based on these premises, Pouyaud and Guichard (2017) suggested that career guidance should prepare people to be engaged in aspects of life that might lead to inclusive and sustainable global development. In other words, it is essential to support individuals to think about forms of active life that promote sustainability and inclusion.

Santilli et al. (2020), based on the Life Design approach and considering the new and global challenges that characterize today's world and societies, emphasized that career guidance should encourage people to look at the global reality and what is likely to happen in the future, to focus less on self, and to recognize that discriminations, inequalities, and barriers exist and limit inclusion and sustainability. Career guidance professionals should also encourage people to take on work that combats these negative inequities and creates alternatives for improving the wellbeing of humankind and the world.

\section{Career and Life Design for an Inclusive and Sustainable Future}

Given the premises of careers and work thus far pertaining to the Life Design approach and considering recent reflections in the field of career guidance discussed previously, there are a number of ways in which this approach can contribute to career guidance practices that foster inclusion and sustainability, particularly with adolescents and marginalized populations.

Inclusive and sustainable vocational guidance for adolescents. Adolescents today find themselves planning their future career in a social context characterized by globalization, the hegemony of neoliberal politics, rapid technological advancements, precariousness, and unemployment. There are also a series of social risks, challenges, and environmental issues that have substantial repercussions on adolescent career decision-making and future career planning (Hooley et al., 2018).

Several studies have shown that issues associated with job and work precariousness and unemployment contribute to feelings of discomfort and uncertainty about the future for young people. Such issues and perceptions are also related to low expectations of career success, a sense of hopelessness for the future, a tendency to orient to the present and act without consideration of the future and, overall, the perception that the world of work is full of obstacles capable of compromising their educational and career development (Hatala et al., 2017).

However, lack of awareness of issues pertaining to globalization and market-driven economies and their repercussions on the labour market and 
on future career planning can be a problem. Globalization is fairly widely perceived as a complex phenomenon, characterized by economic, cultural, and exchange aspects. Ginevra, Di Maggio, Santilli, Berti, and Nota (2019) found, however, that adolescents did not consider these issues, including critical issues associated with economic and social disparities (e.g., Myers, 2010).

In the career guidance field, specific career interventions are needed to stimulate greater reflexivity and awareness concerning these phenomena. Furthermore, such interventions are necessary because of the social and political challenges that, in an inclusive and sustainable perspective, young people must consider when thinking about their future. Career guidance should be able to enable young people to think about the challenges they will face in the future. It also should foster the growth and social development of young people by "shifting" from a mostly individualistic, inward-looking, present-oriented vision to a more contextually oriented worldview that includes a focus on society and the common good, social development, and sustainability (Soresi \& Nota, 2020).

The shifting emphasis in career guidance on social phenomena should enhance some form of collective good rather than solely individual empowerment. The central idea is that the management of these challenges requires the collaboration of professionals, multidisciplinary approaches, the use of heterogeneous skills, and a view that underlines how people together can change the future, rather than the single person can change the future (Anderson, Turner, Heath, \& Payne, 2016; Watts, Diemer, \& Voight, 2011).

Further, Di Maggio, Ginevra, Santilli, and Nota (2019) pointed out that the propensity to consider global challenges is associated, directly and indirectly, with hope in achieving personal goals and goals pertaining to the common good, and to a more significant investment in higher education. The latter is important for career guidance professionals in that their role becomes, in part, to prepare future professionals to understand and prevent global threats and find new, complex, and innovative solutions to existing challenges, thus providing promise to them and future generations of a society able to provide wellbeing and satisfaction for all (Peterson \& Helms, 2014).

Considering this, we have developed and tested the effectiveness of the Stay Inclusive, Sustainable, Curious, Cosmopolitan, Aspirant, Etc. project at the Larios Laboratory of the University of Padova, Italy. The focus of this project was to use a Life Design approach to encourage young people to reflect on the future and career planning, taking into account the global challenges that they will face in that future. The project includes a series of assessment instruments that guide young people in the identification of possible future concerns, on 
the one hand, and a series of future scenarios on the other. For example, to get young people to reflect on the future, the questionnaire The future is around the corner... What does it hold? was developed, aimed at encouraging adolescents to reflect on developing sustainable and inclusive contexts. The instrument Thoughts on development and the economy of the future was developed to support young people to reflect on their ideas about an economy for the benefit of all people and society. Additional instruments have been developed to focus the attention of adolescents on resources and skills for planning their future in conditions of uncertainty and insecurity in the labour market, conditions that will likely be present into the near future (Santilli et al., 2020). These skills are, for example, the ability to keep up to date, to be able to engage in Life Design activities even in complex and uncertain situations (Schaufeli, Martinez, Pinto, Salanova, \& Bakker, 2002); optimism, flexibility, persistence, curiosity, and risk-taking (Krumboltz, 2009); and cosmopolitism (Van de Vijver, Van Hemert, \& Poortinga, 2015).

As part of the project, a career guidance intervention was also planned for high school students, titled Looking at the Future and at the University in an Inclusive Way. It is intended to encourage reflections on global challenges and on the contribution that they can make in their educational and career futures. It consists of five didactic units of two hours each, one for each week for a total of five weeks. In the first unit, future emergencies identified by the United Nations are discussed, and students are asked to examine these as they pertain to their hopes and concerns for the future. In the second unit, the 17 Sustainable Development Goals set by the United Nations are presented. The importance of education and self-determination towards the future are discussed to encourage students to reflect on what these can bring to their future and how they could relate those to the United Nations' goals. During the third and fourth meetings, students are invited to think about their possible future visions, taking into account the United Nations' goals. In the last unit, adolescents are helped to identify occupations and professional activities related to their vision, and possible training paths that could help them to acquire knowledge and useful skills to perform them. In line with this, different and extensive academic fields are examined, rather than specific degree courses. This is intended to stimulate participants to reflect on the role that education has in the realization of their visions and the contribution that study and training could make in pursuing the goals identified by the United Nations.

To test the effectiveness of this career intervention, a study was conducted with 92 high school students $\left(M_{\text {age }}=17.21\right.$; $\left.S D=0.62\right)$, randomly assigned 
to either a traditional career intervention group (43 students) or to the treatment "inclusive" career intervention group (49 students). Results highlighted that adolescents in the inclusive career intervention group showed higher levels of career adaptability, career decisiveness, and investment in higher education than did students in the traditional intervention group. Results suggest that this program could be used in school contexts to provide effective career guidance training to large groups of students interested in promoting sustainable and inclusive social contexts.

It should be noted that it is crucial to involve parents and teachers who, if properly trained, can support young people to analyse social phenomena in a more sophisticated manner; and to explore activities, training, and professional paths to which to commit, with the goal of contributing to the construction of sustainable and inclusive social contexts (Pouyaud \& Guichard, 2017).

Inclusive and sustainable career guidance for individuals with vulnerability. The conditions described in the opening pages of this chapter have very real negative consequences, especially for people who are vulnerable, including people with disabilities, immigrants, who are unemployed, or who are early school leavers (Carr \& Batlle, 2015). Prejudices and stereotypes about these marginalized groups persist and tend to be associated with a lack of hope, doubts on one's skills, self-depreciation, and inclinations to focus on one's negative aspects (Millner \& Kim, 2017). Research by Di Maggio, Santilli, Nota, Ginevra, and Soresi (2019) showed, for example, that people with stories of addiction have to face persistent contextual barriers, such as negative evaluations from others, lack of social/economic support, and prejudice in working environments. All these factors strain their psychological stability and make it difficult for them to project or re-project their working future.

Considering all of the above, it is clear that when dealing with inclusive and sustainable career guidance, it is more important to give voice to people who are vulnerable so as to support them to recognize external and contextual factors that affect their stories in relation to the broad sociopolitical system in which they live. It is important to help marginalized people reconsider their life stories, underlining the positive or negative role that the context played in their working life and to help them think about how much that could affect their construction of the future. On the one hand, this process creates forms of consciousness and awareness, on the other hand it creates procedures of critical reflection, which help to reduce the "weight" of experiences of failure, difficulties, and discomfort (Kenny, Blustein, Gutowski, \& Meerkins, 2018; Sanchez Carmen et al., 2015). 
Kenny et al. (2018) suggested, in line with what has also been highlighted by Hooley et al. (2018), that career practitioners should, first of all, help people to consider the sociopolitical circumstances that affect their life stories. Career practitioners should analyse, explicitly, the power disparities and sociopolitical inequities that exist that result in bias and discrimination. They also should understand, through their clients' life stories, their meaningful, concrete, working and life experiences, and, as a consequence, foster guidance to account for these experiences. Finally, they should help individuals to challenge negative stereotypes and to reduce the perception of guilt.

In this context, guidance professionals might call particular attention to the courage a person has shown in dealing with difficult circumstances, thus emphasizing a human virtue (Putman, 2010). Courage is a protective mechanism for coping with situations of discrimination and vulnerability (Putman, 2010; Santilli et al., 2020), a combination of strengths that include bravery, persistence, integrity, and vitality. It promotes "the exercise of will to accomplish goals in the face of opposition, either external or internal" (Peterson \& Seligman, 2004, p. 199).

In line with this, Santilli et al. (2020) have involved young people in envisioning themselves in precarious conditions so as to give them a voice in those situations, starting from their stories of courage. These young people are asked to tell a real personal story of courage. In particular, the participants are told:

the purpose of this interview is to better understand the experience of courage that people exhibit in their life or professional life. Life is often complex and difficult, and for this reason, it requires patience, perseverance and courage. In your experience, have you ever been courageous? If yes, can you try to describe a situation in which you were a courageous person?

Analyses were conducted on answers provided and two core themes emerged. The first was connected to indecent and undignified working conditions and the second core theme was connected to neoliberal ways of conceptualizing the person and work. The first core-theme concerned unacceptable requests regarding the working environment in terms of time, place, and salary (e.g., "I call it exploitation because I was forced to work in the company without a contract. I signed nothing and I worked: this is courage."). Other stories were about proposals for odd jobs and overbearing promises ("I had the courage to try a little bit of everything. So many times I found myself doing odd jobs ... he made me do everything, and I did learn anything"). Other requests identified were requests that were urgent without a compelling reason, requests to make 
future life decisions without having time to reflect ("I was called to work in Malta overnight ... the departure would have been the following week"). There were also stories about discriminatory conditions ("Once in a bar where I worked for four months as a bartender, I met an owner who reminded me of the devil. He treated me like a slave.").

The second core-theme concerned the neoliberal work context. Specifically, two sub-themes were identified: the idea that the responsibility for one's failures and successes is only personal ("only sometimes I think it's not all my faul because I can't find a job. I think that this is not due to my characteristics but to a global situation") and competition in working contexts ("Courage is facing the pressure they put on you ... they make you know right away that it is a ruthless competition for that position").

When focusing on courage, it is possible to identify positive actions performed by people and to value them. People can be helped to adopt an assertive stance that can help them connect to society and reshape their lives in the face of scarcity, marginalization, and oppression (Kenny et al., 2018; Sanchez Carmen et al., 2015).

The examination of these situations can also be the basis for helping people face categorizations and labelling that tend to foster self-depreciation and the propensity to focus on one's negative aspects (Millner \& Kim, 2017). People should also be helped to reflect upon the propensity to internalize the myth to which the neoliberal culture has accustomed us: being self-entrepreneurs (Santilli et al., 2020). According to that myth, individuals are actually those who determine their chances of success and failure. This mistakenly leads people to think that they are entirely in charge of their problems and their failures. These beliefs can become "millstones" that people are forced to live with and that may often hinder a courageous re-design of one's existence (Kenny et al., 2018).

The scientific and experiential knowledge that practitioners collect through an attention to barriers and negative context conditions may be used, at this point, to breathe life into guidance activities dealing with awareness and activism. This can also be accomplished through the involvement of private and public institutions' stakeholders and through educational interventions aimed at promoting the creation of inclusive scholastic, working, and community contexts. These contexts have to directly address and eliminate discriminations and inequalities and have to foster active involvement of all (Appadurai, 2004; Di Maggio, 2019). 


\section{Conclusions}

The socioeconomic conditions that have characterized the last few decades, specifically globalization and neoliberalism, impact our daily life as well as the economics and societal structures of countries, creating an inextricable intertwining of progress and threats. The threats, as described in this chapter, have serious implications for career decisions and wellbeing of young people, particularly young people who are vulnerable, and can lead to limitations quality and satisfying futures. All of this leads to the need to identify critical steps in career guidance that can lead the field towards efforts to promote inclusion, sustainability, and to combat inequality and discrimination.

Such a recalibration begins with career guidance professionals assume the role of change agents; to make it clear that career guidance is no longer just about the self, but about the person within the context of experiences and environments. Is also important to reflect on the negative consequences of contexts that are not inclusive and work environments and conditions that are not respectful, and to find ways to act to change negative and dehumanizing environmental and social conditions (Soresi, Nota, Ginevra, Santilli, \& Di Maggio, 2019). To further this agenda, Soresi et al. (2019) developed (in partnership with a wide array of researchers and practitioners) a Memorandum on Guidance and on Career Counseling, to address issues that need to be addressed to ensure that populations with vulnerability are included. This memorandum states that career scholars, professionals, and practitioners should, among other things:

- anchor their reflections and promote, through their interventions, those theoretical models and practices that connect scientific rigour to a specific vision of the future, in terms of sustainability, equity, and inclusion;

- suggest analysing the influence of contextual factors in determining needs, successes, and failures;

- maximize preventive and early intervention opportunities, especially for members of vulnerable communities;

- detect and remove barriers that may reduce the involvement of every person into social, educational, and working life;

- collaborate with other agencies, services, and professionals interested in sustainable development, social activism, and in people's wellbeing;

- provide psychosocial and psycho-educational support, particularly for people from vulnerable and marginalized groups; 
- mobilize complex processes that take into account interpersonal, cultural, social, environmental, economic, and political-institutional factors to enable agentic action and encourage and produce change dynamics;

- use qualitative and quantitative procedures to highlight the effects of career guidance on choice processes and on processes regarding career design for groups and people (e.g., the ability to explore and get to know educational and professional contexts, the ability to deal with and sort out difficult situations, the ability to pursue fair, inclusive and sustainable development's goals and ambitions, etc.); and

- foster equal opportunities in educational and professional contexts and the reduction of any form of discrimination, of undignified jobs, of underemployment and precariousness.

\section{References}

Alvaredo, F., Chancel, L., Piketty, T., Saez. E., \& Zucman, G. (2018). World inequality report. Retrieved from: https://wir2018.wid.world/files/download/wir 2018-full-report-english.pdf.

Anderson, C., Turner, A. C., Heath, R. D., \& Payne, C. M. (2016). On the meaning of grit... and hope... and fate control... and alienation... and locus of control... and... self-efficacy... and... effort optimism... and.... The Urban Review, 48(2), 198-219.

Appadurai, A. (2004). The capacity to aspire: Culture and the terms of recognition. Culture and Public Action, 59, 62-63.

Asante, S. (2002). What is inclusion?. Toronto: Inclusion Press.

Carr, S., \& Batlle, I. C. (2015). Attachment theory, neoliberalism, and social conscience. Journal of Theoretical and Philosophical Psychology, 35(3), 160-176.

Chomsky, N., \& Polychroniou, C. J. (2018). Ottimismo (malgrado tutto). Capitalismo, Impero e Cambiamento Sociale [Optimism (despite everything). Capitalism, empire and social change]. Milano, Italy: Ponte alle Grazie.

Dardot, P., \& Laval, C. (2013). La Nuova Ragione del Mondo. Critica della Razionalità Neoliberista [The new reason for the world. Criticism of neoliberal rationality]. Roma, Italy: Derive Approdi.

Di Maggio, I. (2019). La rilevanza dell'orientamento e del career counselling per un futuro di qualità per tutti [The importance of career guidance and career counselling for a quality future for all]. In S. Soresi, L. Nota, \& S. Santilli (Eds.), Il Contributo dell'Orientamento e del Counselling all'Agenda 2030. Padova, Italy: Cleup. 
Di Maggio, I., \& Shogren, K. (2017). Any given context (school, work, society) will be considered inclusive only if... In L. Nota \& S. Soresi (Eds.), For a Manifesto in favor of inclusion. Concerns, ideas, intents and passwords for inclusion (pp. 29-34). Firenze: Hogrefe.

Di Maggio, I., Ginevra, M. C., Santilli, S., \& Nota, L. (2019, October). Global challenges, social hope and investment in training for an inclusive e sustainable future goals. Paper at Italian Conference of Career Guidance, University of Catania, Italy.

Di Maggio, I., Santilli, S., Nota, L., Ginevra, M. C., \& Soresi, S. (in press). Orientamento e progettazione professionale in persone con storie di dipendenza [Career and Life Design for people with Substance Abuse Disorder]. In S. Soresi, L. Nota, \& S. Santilli (Eds.), Il Contributo dell'Orientamento e del Counselling all'Agenda 2030. Padova: Cleup.

Gati, I., Garty, Y., \& Fassa, N. (1996). Using career-related aspects to assess personenvironment fit. Journal of Counseling Psychology, 43(2), 196-206.

Ginevra, M. C., Di Maggio, I., Santilli, S., Berti, A. E., \& Nota, L. (2019, September). La percezione dell'economia in un gruppo di giovani coinvolti in un progetto di orientamento inclusivo [The economic perception in a group of young people involved in an inclusive vocational guidance intervention]. Paper presented at XXXII AIP National Conference. Naples, Italy.

Guichard, J. (2018). Life design interventions and the issue of work. In V. CohenScali, J. P. Pouyaud, M., Drabik-Podgorna, G., Aisenson, J. L. Bernaud... \& J. Guichard (Eds.), Interventions in career design and education: Transformation for sustainable development and decent work (pp. 15-28). Paris: Springer, Cham.

Hansmann, R., Mieg, H. A., \& Frischknecht, P. (2012). Principal sustainability components: An empirical analysis of synergies between the three pillars of sustainability. International Journal of Sustainable Development and World Ecology, 19(5), 451-459.

Hatala, A. R., Pearl, T., Bird-Naytowhow, K., Judge, A., Sjoblom, E., \& Liebenberg, L. (2017). "I have strong hopes for the future": Time orientations and resilience among Canadian Indigenous youth. Qualitative Health Research, 27(9), 13301344.

Hirschi, A., \& Dauwalder, J. P. (2015). Dynamics in career development: Personal and organizational perspectives. In L. Nota \& J. Rossier (Eds.), Handbook of life design: From practice to theory and from theory to practice (pp. 27-39). Göttingen: Hogrefe.

Holland, J. L. (1959). A theory of vocational choice. Journal of Counseling Psychology, $6(1), 35-45$.

Hooley, T., Sultana, R., \& Thomsen, R. (2018). Career guidance for emancipation: Reclaiming justice for the multitude. London: Routledge.

Kenny, M. E., Blustein, D. L., Gutowski, E., \& Meerkins, T. (2018). Combatting marginalization and fostering critical consciousness for decent work. In V. Cohen-Scali, J. Rossier, \& L. Nota (Eds.), International perspectives on current 
research in career counseling and guidance. Building careers in changing and diverse societies (pp. 55-73). New York: Springer.

Krumboltz, J. D. (2009). The happenstance learning theory. Journal of Career Assessment, 17(2), 135-154.

Lent, R. W., Brown, S. D., \& Hackett, G. (1994). Toward a unifying social cognitive theory of career and academic interest, choice, and performance. Journal of Vocational Behavior, 45(1), 79-122.

Milanovic, B. (2017). Ingiustizia Globale: Migrazioni, Disuguaglianze e il Futuro della Classe Media [Global injustice: migration, inequalities and the future of the middle class]. Roma, Italy: LUISS University Press.

Millner, U. C., \& Kim, M. (2017). Perspectives on work and work-related challenges among Asian Americans with psychiatric disabilities. Asian American Journal of Psychology, 8(3), 177-189.

Myers, J. P. (2010). Exploring adolescents' thinking about globalization in an international education program. Journal of Research in International Education, 9(2), 153-167.

Nota, L., \& Rossier, J. (2015). Handbook of life design: From practice to theory and from theory to practice. Göttingen: Hogrefe.

Nota, L., Soresi, S., Di Maggio, I., Santilli, S., \& Ginevra, M. C. (2020). Sustainable development, in career counseling and career education. London: Springer.

Nota, L., Soresi, S., Ferrari, L., \& Ginevra, M. C. (2014). Vocational designing and career counseling in Europe: Challenges and new horizons. European Psychologist, 19(4), 248-259.

O'Reilly, J., Lain, D., Sheehan, M., Smale, B., \& Stuart, M. (2011). Managing uncertainty: The crisis, its consequences and the global workforce. Work, Employment \& Society, 25(4), 581-595.

Owens, J. (2015). The social model of disability and its application to dentistry. Dental Nursing, 11(8), 448-450.

Peterson, C., \& Seligman, M. E. (2004). Character strengths and virtues: A handbook and classification. Oxford: University Press.

Peterson, P. M., \& Helms, R. M. (2014). Internationalization revisited. In A. Maldonado-Maldonado \& R. M. Bassett (Eds.), The forefront of international higher education (pp. 101-111). Dordrecht: Springer.

Pouyaud, J. (2015). Vocational trajectories and people's multiple identities: A life design. In L. Nota \& J. Rossier (Eds.), Handbook of life design: From practice to theory and from theory to practice (pp. 59-74). Göttingen: Hogrefe.

Pouyaud, J., \& Guichard, J. (2017). A twenty-first century challenge: How to lead an active life whilst contributing to sustainable and equitable development. In T. Hooley \& R. G. Sultana (Eds.), Career guidance for social justice (pp. 31-45). London: Routledge.

Purvis, B., Mao, Y., \& Robinson, D. (2019). Three pillars of sustainability: In search of conceptual origins. Sustainability Science, 14(3), 681-695. 
Putman, D. A. (2010). Philosophical roots of the concept of courage. In C. L. S. Pury \& S. J. Lopez (Eds.), The psychology of Courage: Modern research on an ancient virtue (pp. 9-22). Washington, DC, USA: American Psychological Association.

Sanchez Carmen, S. A., Dominguez, M., Greene, A. C., Mendoza, E., Fine, M., Neville, H. A., et al. (2015). Revisiting the collective in critical consciousness: Diverse socio-political wisdoms and ontological healing in sociopolitical development. Urban Review, 47, 824-846.

Santilli, S., Di Maggio, I., Ginevra, M. C., Nota, L., Soresi, S. (2020) Life Design, inclusion and sustainable development: constructs, dimensions and new instruments to stimulate a quality future design for all. In M. Yuen, W. Beamish, V. S. Solberg (Eds.), Careers for students with special educational needs-Perspectives on development and transitions from the Asia-Pacific region. Springer Education \& Language.

Savickas, M. L. (2005). The theory and practice of career construction. Career Development and Counseling: Putting Theory and Research to Work, 1, 42-70.

Savickas, M. L. (2011). Constructing careers: Actor, agent, and author. Journal of Employment Counseling, 48(4), 179-181.

Savickas, M. L., Nota, L., Rossier, J., Dauwalder, J. P., Duarte, M. E., Guichard, J., ... \& Van Vianen, A. E. (2009). Life designing: A paradigm for career construction in the 21st century. Journal of Vocational Behavior, 75(3), 239-250.

Schaufeli, W. B., Martinez, I. M., Pinto, A. M., Salanova, M., \& Bakker, A. B. (2002). Burnout and engagement in university students: A cross-national study. Journal of Cross-Cultural Psychology, 33(5), 464-481.

Shogren, K. A., Wehmeyer, M. L., Schalock, R. L., \& Thompson, J. R. (2016). Reframing educational supports for students with intellectual disability through strengths-based approaches. In M. L. Wehmeyer \& K. A. Shogren (Eds.), Handbook of research-based practices for educating students with intellectual disability (pp. 25-38). London: Routledge.

Soresi, S., \& Nota, L. (2020). L'Orientamento e la progettazione professionale [Career counselling and vocational designing]. Bologna, Italy: il Mulino.

Soresi, S., Nota, L., Ginevra, M.C., Santilli,S., Di Maggio, I. (2019). Per uno sviluppo sostenibile, dignitoso ed inclusivo per tutti: una Carta-Memorandum dell'Orientamento e del Career counseling [For a sustainable, dignified and inclusive development for all: Carta-Memorandum for Career Counseling]. In S. Soresi. L. Nota, \& S. Santilli (Eds.), Il Contributo dell'Orientamento e del Counselling all'Agenda 2030. Padova, Italy: Cleup.

Super, D. E. (1980). A life-span, life-space approach to career development. Journal of Vocational Behavior, 16(3), 282-298.

Van de Vijver, F. J., Van Hemert, D. A., \& Poortinga, Y. H. (2015). Multilevel analysis of individuals and cultures. Hove, UK: Psychology Press. 
Watts, R. J., Diemer, M. A., \& Voight, A. M. (2011). Critical consciousness: Current status and future directions. New Directions for Child and Adolescent Development, 2011(134), 43-57.

WCED. (1987). Our common future. Oxford, UK: Oxford University Press.

Wehmeyer, M. L., Nota, L., Soresi, S., Shogren, K. A., Morningstar, M. E., Ferrari, L., ... \& Di Maggio, I. (2019). A crisis in career development: Life designing and implications for transition. Career Development and Transition for Exceptional Individuals, 42(3), 179-187.

Young, R. A., \& Collin, A. (2004). Introduction: Constructivism and social constructionism in the career field. Journal of Vocational Behavior, 64(3), 373388.

Open Access This chapter is licensed under the terms of the Creative Commons Attribution 4.0 International License (http://creativecommons.org/licenses/by/4.0/), which permits use, sharing, adaptation, distribution and reproduction in any medium or format, as long as you give appropriate credit to the original author(s) and the source, provide a link to the Creative Commons license and indicate if changes were made.

The images or other third party material in this chapter are included in the chapter's Creative Commons license, unless indicated otherwise in a credit line to the material. If material is not included in the chapter's Creative Commons license and your intended use is not permitted by statutory regulation or exceeds the permitted use, you will need to obtain permission directly from the copyright holder. 